\title{
The Importance of Piagetian Reference for the Elucidation of Conceptual Development in Chemistry
}

\author{
Aldo Sena de Oliveira, Anderson Luiz Machado, Ana Carolina Araujo da Silva \\ Universidade Federal de Santa Catarina, Blumenau, Brazil \\ Email: aldo.sena@ufsc.br
}

Received 9 February 2016; accepted 25 March 2016; published 28 March 2016

Copyright (C) 2016 by authors and Scientific Research Publishing Inc.

This work is licensed under the Creative Commons Attribution International License (CC BY).

http://creativecommons.org/licenses/by/4.0/

c) (†) Open Access

\begin{abstract}
Genetic epistemological studies underlie the development of methodological proposals for education. In order to reach an inference about the cognitive structure of children and adolescents, experiments based on the Piagetian clinical method are performed with infralogical operations. In achieving these inferences, it is suggested to carry out chemistry experiments seeking representation of children and adolescents with respect to the actions and reactions of said experiments. In this study, we present for the first time in the literature correlations between the Piagetian clinical method and classic experiments performed in chemistry labs. Thus seeking the contributions of chemistry to explain phenomena and support the learning of children as an alternative to the education and consequentially development of children.
\end{abstract}

\section{Keywords}

Chemistry Education, Piaget, Constructivism

\section{Introduction}

In Brazil, chemistry is taught for the first time as a separate subject in grades nine of elementary school. The chemistry disciplines are part of the curriculum only high school. It is prior to that there is an integrated science course in grades one and eight (elementary school), where chemistry has a limited participation.

The Brazilian government provides guidelines for the study of natural sciences in elementary school, through the joint approach of the areas that comprise the curriculum of science, but in practice this does not occur. According to the program of chemistry textbooks adopted by the Brazilian government as references for public education (Fonseca, 2010; Mortimer \& Machado, 2010; Castro et al., 2010; Antunes, 2013) that were used until 
the school year 2013 to 2015, many abstract chemical concepts at the submicro (molecular, atomic and subatomic) level were introduced quite early in the course: atomic and molecular structure, relative molecular mass, the mole, molar volume, Avogadro's constant, the building-up of the periodic table on the basis of the atomic (electronic) structure, chemical bonds (ionic and covalent), chemical reactions, stoichiometric calculations, organic and inorganic functions, electrochemistry, kinetics, thermodynamics, acidity and basicity and others.

The large amount of content and information is difficult the correlations. Whereas what only is useful and what gives pleasure can be stored in memory, most of the concepts developed in the subject of chemistry, which are difficult understanding and if not relate directly to the student, will hardly meant for students. Understanding chemistry is difficult for most students. Much of the concepts requires more than a simple lecture and requires a lot of resources so that they can be internalized. Many of these difficulties are caused by daily life experiences of chemical phenomena which students bring into the classroom. Although physical and chemical changes are visible as changes of the state of matter or changes in other properties of the substance, like color, several studies have shown that secondary students do not grasp these chemical concepts (Andersson, 1990; Ben-Zvi et al., 1986; Bou Jaoude, 1991).

Unsurprisingly these concepts require formal operational reasoning in the Piagetian sense, at the same time pose a heavy burden on students' working memory (Herron, 1978). In addition to this fact, combined with the very low teaching time allocated to chemistry (just one fiftyminutes period per week per year), as well as the lack of experiment/practical work from teaching, must be the causes of the very low knowledge of basic chemistry of Brazilian students.

The last 20 years, research on the role of students' pre-instructional knowledge, "misconceptions" (Driver \& Easley, 1978), “preconceptions” (Driver \& Easley, 1978), “alternative frameworks” (Driver \& Erickson, 1983), or "children's science" (Osborne \& Freyberg, 1985) showed that these notions limited students' understanding in science and were often different from the commonly accepted scientific concepts (for an overview of these studies, see Carmichael et al., 1990; Pfundt \& Duit, 1994).

Chemistry education research has one of its major targets to suggest new ways and methods of teaching chemistry. These ways and methods must not only be based on the proper educational theory (educational psychology, developmental psychology, science education), they must also be given support by experimental empirical work.

In this paper, we describe part of a research that is being developed in Brazil, which makes use of chemical experiments with operational tests on the physical knowledge. The central idea is analyze the understanding of children about experimental situations involving chemical concepts. These situations can provide elements for the evaluation of effects on children's learning.

This work is based on Piaget's work and the genetic epistemology analyzing their implications for education, with a view to child development and learning.

\section{Constructivism and Education}

Jean Piaget is renowned for constructing a highly influential model of child development and learning. In Piaget's theory of the construction of knowledge, called the theory of genetic epistemology, logico-mathematical knowledge is progressively constructed by a child in interaction with a world. Piaget's theory is based on the idea that developing child builds cognitive structures or networked concepts for understanding and responding to physical experiences within his or her environment (Piaget, 1983). The construction of these structures is said to be explained by four factors: maturation, physical experience, social experience, and equilibration (or selfregulation) (Piaget, 1970).

Most of the discussion of Piaget's work among science educators has focused on the transition between the concrete operational and formal operational stages and ways in which instruction can be revised in light of this model (Bodner, 1986). A great deal of attention has been given to the work of Piaget, pointing out that there may be a connection between age (maturity) and the complexity of thinking of which a learner is capable. Thus, Piaget's followers (Herron, 1978; Lawson \& Karplus, 1977) argue that students who have not attained formal operational ability will not able to comprehend meaningfully abstract concepts and principles of science.

The central question of genetic epistemology then is: how to increase (as a plurality) knowledge? By which process does a science pass from a determined knowledge, later judged as insufficient, to another determined knowledge then judged superior by the common consciousness of that discipline's practitioners? As such all epistemological problems are encountered, but in a historical and critical perspective and no longer in improvi- 
sation (Piaget, 1973: p. 33).

According to the genetic epistemology theory, as requests arise the intelligence structures go building themselves and, from new requests, the subject has the ability to rearrange them, experiencing constant assimilation mechanisms of new objects to already existing processes and knowledge expansion mechanisms known as accommodation. The result of successive assimilations and accommodations is called, by Piaget, equilibration (a central concept of his constructivist theory of knowledge). So when the structures that the subject has built does not allow them to assimilate a new object of knowledge, i.e., the determined object is resistant, it causes a disturbance in the subject triggering disequilibration.

The stages of intelligence development provided by psychogenetic theory are as follows: the sensorimotor stage (of practical intelligence), the concrete operational stage (which is initially an intuitive intelligence and then operational, based on reciprocity of thought) and the formal stage (when you can act and think under hypotheses and abstractions). These stages are perhaps the best known aspect of Piaget's theory. Unfortunately, it is also the source of some ill-founded criticism of his work, for example the fact that Piaget would only investigate his children, in the case of the sensorimotor stage, or that "Piaget's children" were "somewhat delayed" once some studies found answers regarding a determined stage in children at a younger age than those outlined by his theory.

The Piagetian tests to diagnose operation level (research tools elaborated upon by the author as a method to investigate the cognitive developmental level of the child) have been replicated in many countries and in different studies. The results of these investigations are exactly similar to those pointed out by Piaget, especially in what they tell us with regard to successive (not chronological) and integrative stages of character, because each of them is necessary for the formation of the next. Piaget’s studies were very complex and very much influenced knowledge in the field of psychology, especially human development psychology among other areas of knowledge.

\section{Chemistry for Children: A New Look for Learning Science}

If teaching Chemistry is already a challenge for any education level, imagine doing that for children. Chemistry is an experimental, theoretical and abstract science. Teaching this science means to understand the nature of the scientific knowledge, as well as the goals of a scientific education. So, teach that science for children is not a simple or easy task; it's a challenge for all science teachers.

Science/Chemistry teaching is considered as a human activity that has a speech and a specific language (Mortimer \& Scott, 2003). For learning Science, students must have the opportunity to understand the scientific concepts, but they also must take in some aspects from epistemology and nature of the science (Driver et al., 1996). Studies of Driver et al. (1996) reinforce that learning science is related to the fact of putting the students in a new-meaning world and involving them in different ways of thinking, seeing and explaining the world. By this teaching perspective, child comes into contact with another language: the scientific one, which brings characteristics from another culture, the scientific one. Therefore, through learning science, child comes into contact with two different languages: the scientific one and that from his/her everyday life.

For Chassot (2014) "the chemical knowledge must traverse the whole area of elementary school science, and not be restricted to an isolated class". We believe that the teaching of chemistry for children should assist them in understanding how the world works and discussion of topics as food and alimentation, air, water, soil, the environments, the neighborhood, the city among other relevant topics. Only in this way that the teaching of chemistry will have a meaningful to children.

Along the same lines, Howard et al. (1989) proposed a chemistry laboratory use program for Elementary School. In this research, the authors found out that children liked classes with experimental activities much more than lectures. They also pointed out that inclusion of these experimental activities in teaching enriched students' vocabulary, and their questions and recorded comments became more numerous and sophisticated. For these authors, there is a need to introduce children in the ways of representing the world and in scientific practices, enabling to know a new language to describe, represent and analyze the world around them, which is regarded as enculturation in science, that means, learning science in its use, accessing produced knowledge and experiencing ways of doing and thinking about science.

The importance of experimentation in teaching Chemistry has been the subject of several theories in recent decades. Experimentation can be an effective strategy for the content to be worked on and for solving real problems that allow for contextualized teaching. The research stimulates students to make hypotheses, questions and 
to discuss the phenomena presented during the lesson. In this process of building knowledge, the experiments must give students the opportunity to perform, record, discuss with colleagues, reflect, make hypotheses, evaluate the hypotheses and explanations and discuss with the teacher during every stage of the experiment (Oliveira \& Caminha, 2014).

It's interesting to notethere are still few studies that address Chemistry Teaching for children. This seems to be a discussion that must be thorough, including empirical studies in this area. Although there is a wide acceptance about the importance of Science Education for children, very little has been researched.

A modern thought that seeks the unusual synthesis between the biological and logical-mathematical seems to find its limits in an even more unusual deconstruction that tends systematically all thought at present: the self developing in an essentially clarified way (Abreu et al., 2010).

Reported for the first time in the literature, this work proposes to show the importance of the Piagetian reference for the elucidation of conceptual development in Chemistry, based on experiments with infralogical operations and experiments of thermodynamics and calorimetry, affirming the importance of using experiments related to Chemistry, including them in the early grades of schooling (Figure 1).

\section{Methodology}

Children and adolescents between the ages of 4 and 18 were randomly selected among those living in the interviewer's neighbourhood. To facilitate the process the study was conducted during school holidays. Parents were informed of the adopted procedures and then signed an informed consent form authorizing for both the participation and photographing of the children and adolescents. The interviewer was one of the authors of this work. The tests were performed individually.

The main objective of the operational tests was to determine the degree of acquisition of key notions of cognitive development, detecting the level of thinking reached by the child, i.e. the level of structure with which it operates (Weiss, 2003).

\subsection{Experiments with Infralogical Operations}

\subsubsection{Conservation of Weight}

Two clay balls of the same weight were presented to the child while saying, "take these two balls. Do they have the same weight?” In the case that a child said one was heavier than the other the child was asked to make them the same weight, taking the excess weight from the heavier ball. Both balls were placed on the table with one of them being shaped into a cylinder. The child was asked which was heavier, the ball or the cylinder, without being allowed to grab either of them. The child should answer the question without touching the ball or the cylinder.

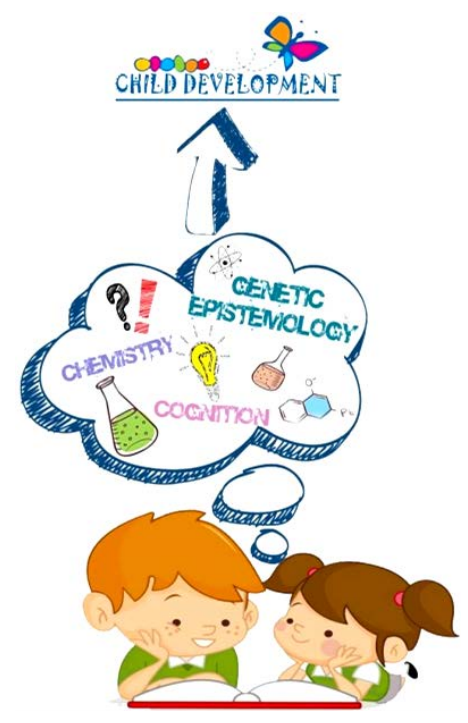

Figure 1. The chemistry, genetic epistemology and child development. 


\subsubsection{Conservation of Discrete Amounts}

Six toothpicks forming a row were placed in front of the child who was then asked, "how many toothpicks are there here?” Even if the child did not know how to count, a second row with the same number of toothpicks as the first was placed in front of the child while keeping a small distance between the toothpicks. The child was then asked, "and now? Does the second row have more or less toothpicks as the first? Why? How do you know?"

\subsubsection{Reversibility}

The child was presented two thin bottles (A and B) containing equal amounts of coloured water and asked, "which of these two do you think has more water?" After the child responded saying they were equal they were asked to pour the contents of bottle B into a new bottle, C, which was short and wide. To conclude they were asked, "and now, which of the two has more?"

The chemistry experiments (Matheus, 2010) which will be described below were the basis for discussion involving changes in the colourimetric plane, i.e. from the colours (colourimetric) and physical states by observing the alterations in the temperature of the bodies (thermodynamics).

\subsubsection{Thermodynamics: Ice and Salt}

Reagents and materials: ice, coarse salt, cup, 2 different sized plastic bags, small disposable coffee cup, water.

The ice was broken into small pieces. A cup of crushed ice was placed into the large plastic bag. The same cup was filled with salt and added to the large bag little by little while mixing the crushed ice. A little water (in the disposable cup of coffee) was placed into the small plastic bag, closed and placed into the larger bag.

Note: by placing salt on the ice its melting point is lowered and thus its melting temperature will also be lower. For the ice to melt it draws the heat from the water in the smaller bag which then freezes. The child was asked, "What happened? How do you think it happened? Why?"

\subsubsection{Colourimetric: Acid/Base Indicators}

Reagents and materials: phenolphthalein, water, transparent cups, lemon, colourless vinegar, baking soda and powdered soap.

The phenolphthalein solution was prepared; a few drops of lemon juice were added to one cup and a few drops of vinegar to another.

What happens: these substances have the property of changing colour in the presence of acids and bases. The idea of acids and bases arises when we try to group substances that have similar chemical properties. The variations can be detected by colour changes in the solutions, with the acidic solutions remaining colourless and the basic solutions turning pink in colour. The child was asked, "What happened with the colours? Why do you think this happened? How do you explain this?”

\section{Results and Discussion}

After conducting the chemistry experiments and Piagetian operational tests, a few evidential points to be highlighted remained: the possibility to infer cognitive structures, the effectiveness of the method and the pedagogical implications of a constructivist approach to everyday school life.

First, it is necessary to explain how the children and adolescents were subjected to the tests-all the tests were conducted individually in the interview location, a room where there was a table previously prepared with the objects for experimentation.

Once the tests were started and while the questions were being answered, a form with operational tasks (the basis for subsequent reflections) was filled out.

For Piaget, biological age cannot be considered as defining a level of mental structuring which can be clearly perceived in the analysis from the operational tests. The experiment carried out with the bottles containing coloured liquids, typically receives as an answer the indication that bottle A had a larger volume of liquid once it was poured into a larger bottle regardless of whether or not the child had the knowledge that the bottles had the same volume. This kind of response is typical of a pre-operational child but was also encountered in adolescents. This can be evidenced by the consideration of a few factors:

- absence of reversibility

- inability to mentally accompany a sequence of facts and as such to interpret the present situation 
- inability to notice the compensation of abstract dimensions like height and width

- strong presence of intuitive reasoning over logical reasoning

In this manner, the presented answer is as significantly important as the characteristics of the mental work performed.

Another operational test which presented a mismatch between biological age and the cognitive developmental stage of several respondents, was the experiment conducted with the toothpicks to assess the conservation of discontinuous quantities. The resolution of this experiment presupposes activities involving the principles of invariance and reversibility, which should show up between the ages of 7 and 8 . Although most of the respondents knew how to count, several of them said that the row of spaced toothpicks had the greater number.

These responses brought important contributions to the understanding of those attributed to the chemistry experiments. When the pre-operational children were questioned as with the colourimetric and thermodynamic experiments, egocentric logic defining mental logic and operating psychological processes was observed. Egocentrism in the language of children implies the absence of the need, on the part of the child, to explain what they say, once they are sure they are being understood. Thus, according to Coutinho \& Moreira (2001) egocentrism is responsible for pre-logical, pre-causal, magical, animistic and artificialist thinking with no reflection. The child's reasoning is neither deductive nor inductive, but transductive, going from individual to individual; it is not logical for the judgement to be centered on the subject, their past experiences or subjective relationships that they establish in function of their reasoning. The desires, motivations and all the conscious characteristics, moral and affective, are attributed to things (animism). The child thinks, for example, that the dog barks because he misses his mother, however, for children who are 5 or 7 years old, the internal psychological processes have physical reality: they believe that thoughts are in the mouth and dreams in the bedroom. From this confusion between real and unreal arises the aritificialist explanation, according to which, if things exist it is because someone made them (Coutinho \& Moreira, 2001).

Thus, the egocentric representation of a child's thinking can be recognized in the statements to follow:

“The color changed because I put" (4 year old).

Thinking based on egocentric logic typical in children between the ages of 2 and 7, where internal processes are highly targeted to the indifference of the inner self and the reality that encircles them.

“The colour didn't change because it's only a little" (6 year old).

Egocentric thinking based on the intuitive and syncretic dimension of thought, where undue associations can often occur once the child has focused only on the physical quantities to define their mental processes.

“...the powder puts colour in the water...” (8 year old).

A childhood belief, typically operational, which allies itself to the transductive dimension of thought where the child tries to make a logical connection between the elements. In this case, the colourimetric can also be understood according to the magical-phenomenalist interpretation of children's thinking where the powder, endowed with a magical and mysterious force, could colour the liquids in question.

“The freezer dries the water and it starts turning into ice..." (11 year old).

A childhood belief, based on the animist dimension of egocentric thought, which according to Piaget (1926), gives life and intentionality to objects.

"...the colour changed because I put the powder in the alcohol and then the bleach..." (10 year old).

A childhood belief, also defined by egocentric logic, where the answers appear in the first person and with intuitive logic based on the juxtaposition to repeat the procedure as a response to the question.

“...the refrigerator takes the power out of the water...” (6 year old).

Egocentric logic, typically operational, based on the magical-phenomenalist interpretation of thought as if the refrigerator could have some intentionality in its mechanical workings, of water heat removal in a physical transformation.

“...it's because when we put water in the refrigerator it loses the forces of its state...” (14 year old). 
Formal operational logic, defined by the adoption of consciousness of abstract thought with modifications of the understanding of scientific terms and preoccupation in giving satisfactory answers.

The above statements affirm the egocentric character in the manifestations of children's ideas and denotes, in the case of the sciences, the cognitive disorders and conflicts that engender an attempt at conceptual change. To believe that the water is endowed with a magical force that permits it to flow through the physical environment, or that the refrigerator endowed with a mysterious power can remove the power from the water leaving it in a stiff, dead, skeletal or stopped state, reinforce the magical-phenomenalist interpretation of children's thinking. While reflecting, the child and/or adolescent, intentionally or not, provokes sensitive alterations in the cognitive plane and thus when challenged to think of the physical states and colourimetric alterations typical of chemistry experiments, the possibility of appropriation of new cognitive domains arises. These domains are reflections of new appropriations and translate important pedagogical implications.

Analyzing the statements, you can perceive just how small the appropriation of scientific concepts (and in particular chemistry in the case of adolescents) is. There was no hypothesis that all of the children would know how to respond to questions guided in scientific knowledge because they didn't have the cognitive conditions for it, and yet even if they did enhancements would be necessary for the acquisition of said scientific knowledge. While interviewing the formal-operational adolescents, we could see that the understanding of physical-chemical processes was based on "schooled notions" of physical states. Some made slight confusions in trying to give answers that seemed more elaborate, such as:

"...the pressure of the ice becomes stronger and increases the density of state forces..."

A psychological interpretation of the above statement suggests the incorporation of logical reasoning to the cognitive dimension, resulting from a transition from a simple egocentric assimilation to a process of accommodation. This passage is crucial for the psyche and of paramount importance for the conscious understanding of processes involving scientific concepts and thus for the teaching of science.

Thus, a pedagogical practice which addresses the sciences and chemistry in the content of educational discourse can address important structural modifications and allow:

- Domains of concepts with an increasing level of complexity, expanding the forms of abstraction and as such the mode of operation of logical structures.

- A domain of differentiated vocabulary and further linguistics aspects which can enrich textual productions and highlight new forms of thinking of measurement in such a way that favours the emergence of reflexive processes.

- Socialization of students, since chemistry experiments are generally conducted in pairs, hence the need of the other for the construction of effective structures and morality standards.

- Development and improvement of logical mathematical reasoning and appropriation of logical operations such as grading, classification, multiplication, and compensation among others. Favouring of the overcoming of egocentrism, overcoming of social-cognitive conflicts and the emergence of internal processes.

- Understanding on the part of the teacher of Piagetian theory and as such, the possibility to work with the different cognitive structures understanding their limitations, thus allowing a pedagogical practice that materializes learning.

- Acceleration of cognitive structures.

\section{Final Considerations}

In this manner, it is possible to realize the importance of the existence of pedagogical practices designed for the teaching of chemistry, and also to make use of genetic epistemology in the early stages of classroom learning with a view to childhood development in their social, cognitive and affective spheres.

Activities which involve colourimetric alterations and changes in physical state can allow for a series of discussions in the school environment and make a series of psycho-pedagogical interventions viable, which can be the basis of intellectual progress of children and adolescents.

The mental processes act in correct accordance with the maturation of structures, but biological age cannot be seen as the standard for defining the stages of cognitive development. Once the phases of childhood and adolescent thinking can be analyzed through an egocentric dimension, these cognitive stages or structures can be inferred from chemistry experiments to explain the changes of physical state and through differing maturation standards for a more useful understanding of colourimetric alterations. 
These appropriations are the basis for development of pedagogical proposals enabled in dealing with contemporary complexity and mediating school work, with a view to a differentiated form of schooling and learning.

If on one hand one of the children, aged four, who, according to Piaget, is inserted into a pre-operational logic of thinking, is able to conserve continuous and discontinuous quantities in order to elaborate an abstraction typical of a posterior cognitive stage, then others aged between 11 and 14 do not reach the reversibility of reasoning typical of someone of that age.

It stands out through activities involving chemistry content, that the development of cognitive structures does not accompany biological age, or rather through them it is possible to infer what stage of cognitive development the children are in and thus how it is possible through these activities to assist in said developments.

\section{References}

Abreu, L. C. A. et al. (2010). The Genetic Epistemology of Piaget and Constructivism. Journal of Human Growth and Development, 20, 361-366.

Andersson, B. (1990). Pupils' Conceptions of Matter and Its Transformations (Age 12-16). Studies in Science Education, 18, 53-85. http://dx.doi.org/10.1080/03057269008559981

Antunes, M. T. (2013). Be Protagonist (2nd Edition) São Paulo.

Ben-Zvi, R., Eylon, B., \& Silverstein, J. (1986). Is an Atom of Copper Malleable? Journal of Chemical Education, 63, 6466. http://dx.doi.org/10.1021/ed063p64

Bodner, G. M. (1986). Constructivism: A Theory of Knowledge. Journal of Chemical Education, 63, 873-877. http://dx.doi.org/10.1021/ed063p873

Bou Jaoude, S. B. (1991). A Study of the Nature of Students’ Understanding about the Concept of Burning. Journal of Research in Science Teaching, 28, 689-704. http://dx.doi.org/10.1002/tea.3660280806

Carmichael, P., Driver, R., Holding, B., Phillips, I., Twigger, D., \& Watts, M. (1990). Research on Students' Conceptions in Science-A Bibliography. Leeds: University of Leeds.

Castro, E., Silva, G., Mol, G., Matsunaga, R., Farias, S., Santos, S., DIB, S., \& Santos, W. (2010). Chemistry for the New Generation-Citizen Chemistry (1st Edition), Sao Paulo: New Generation.

Chassot, A. I. (2014) For What/Who Is Useful Teaching? (3rd Edition). Ijuí: UNIJUÍ.

Coutinho, M. T. C., \& Moreira, M. (2001) Educational Psychology. Lê: Belo Horizonte.

Driver, R., \& Easley, J. (1978) Pupils and Paradigms: A Review of Literature Related to Concept Development in Adolescent Science Students. Studies in Science Education, 5, 61-84.

Driver, R., \& Erickson, G. (1983). Theories-in-Action: Some Theoretical and Empirical Issues in the Study of Students' Conceptual Frameworks in Science. Studies in Science Education, 10, 37-60. http://dx.doi.org/10.1080/03057267808559857

Driver, R., Leach, J., Millar, R. and Scott, P. (1996) Young People’s Images of Science. Buckingham: Open University Press. http://dx.doi.org/10.1080/03057268308559904

Fonseca, M. R. M. (2010). Chemistry: Environment, Citizenship, Technology. São Paulo: FTD.

Herron, J.D. (1978). Piaget in the Classroom. Journal of Chemical Education, 55, 165-170. http://dx.doi.org/10.1021/ed055p165

Howard, R. E., Barnes, S., \& Hollingsworth, P. (1989). Chemistry Laboratory Program for Gifted Elementary School Childre. Journal of Chemical Education, 66, 512-514. http://dx.doi.org/10.1021/ed066p512

Lawson, A. E., \& Karplus, R. (1977). Should Theoretical Concepts Be Taught before Formal Operations? Science Education, 61, 123-125. http://dx.doi.org/10.1002/sce.3730610116

Matheus, A. L. (2010). Chemical Head. Lê: Belo Horizonte.

Mortimer, E. F., \& Machado, A. H. (2010). Chemistry. Ed São Paulo: Scipione.

Mortimer, E. F., \& Scott, P. (2003). Meaning Making in Secondary Science Classrooms. Maidenhaid: Open University Press.

Oliveira, G. M. De, \& Caminha, I. R. (2014). Genetic and Physical Education Epistemology: Some Pedagogical Implications. Psicologia Escolar Educacional, 18.

Osborne, R., \& Freyberg, P. (1985). Learning in Science: The Implications of Children's Science. Auckland: Heinemann.

Pfundt, H., \& Duit, R. (1994). Bibliography. Students’ Alternative Frameworks and Science Education (4th Edition). Kiel: IPN. 
Piaget, J. (1926). The Representation of the World in the Child. Translation Rubens Fiúza, Record: Rio de Janeiro.

Piaget, J. (1973). Psychology and Epistemology: Towards a Theory of Knowledge. Record: Rio de Janeiro..

Piaget, J. (1970). Piaget’s Theory (G. Gellerier \& J. Langer, Trans.). In: P.H. Mussen (Ed.), Carmichael's Manual of Child Psychology (3rd Edition, Vol. 1). New York: Wiley.

Piaget, J. (1983). The Origin of Intelligence in the Child (M. Cook, Trans.). Harmonds Worth: Penguin (orig. pub. 1936).

Weiss, M. L. L. (2003). Educational Psychology Clinic: A Diagnostic View of School Learning Problems. DP \& A: Rio de Janeiro. 